\title{
Disaster Risk Reduction: Cases from urban Africa
}

Authored by Pelling, M. and Wisner, B. (ed.)2009. Earthscan: London. 224 pages. ISBN: 978-1-84407-556-0

Reviewed by Willi Faling

Department of Town and Regional Planning

University of Pretoria willi.faling@up.ac.za

Very little has been written on the growing number of urban disaster risk hotspots, or the integration of disaster risk reduction and human settlement planning in Africa aside from publications by the World Bank, United Nations and a few other international organisations. This book aspires to fill these gaps, and I recommend it as essential reading for any urban development or disaster management practitioner or academic concerned with risk reduction in African cities. I also recommended the book for courses on sustainable human settlements, development planning and disaster risk reduction.

What I liked about the book - which is often absent in edited volumes - is the inclusion of a theoretical section on risk in general in urban Africa, as well as a final chapter that concludes on the preceding case studies and proposes recommendations. I also liked the honesty of the authors about the behaviour of the African public, the challenges of urban governance, and the capacity constraints in dealing with disaster risk reduction in Africa. Conversely, the book claims to appreciate disaster risk reduction measures by communities, but few of the case studies draw attention to these efforts. I was furthermore disappointed in the meagre conclusions and recommendations in a few cases, given the thorough descriptions of the challenges.

'Disaster Risk Reduction: Cases from urban Africa' is an appropriate title for this book. The book is structured around three main focus areas. Part I considers urbanisation and disaster risk reduction in general in Africa, Part II presents six case studies on a range of urban disasters in Africa, and Part III proposes a vision for a safer urban Africa.

In Part I Pelling and Wisner review processes of urbanisation, human security and disaster risk reduction from a non-traditional perspective: that Africa is increasingly an urban continent, that disasters are multidimensional, and that Africa has a critical mass of indigenous capacity to manage disaster risk. In the first two chapters they discuss urbanisation and the complexity of human settlements in Africa offering security whilst simultaneously threatening human lives. They explain how the number of excluded and vulnerable urban dwellers are growing due to a number of social, historic, physical, global, health, climate, environmental, market and political shocks. This vulnerability is compounded by a wide continuum and accumulation of risks, the extent of which local action is incapable of meeting, whilst government-led, 
coordinated disaster risk reduction is lacking. The third chapter provides a review of disaster risk reduction activities and stakeholders. Pelling and Wisner acknowledge the significance of both informal and formal approaches to risks, yet name local municipalities as the best placed actor to coordinate urban disaster risk reduction. They propose disaster risk reduction interventions in the areas of development planning, development regulation, risk management, and risk response.

Part II presents detailed case studies from six different countries. Each case study includes specific background information on urbanisation processes, a history of disasters in the city and an analysis of processes that lead to the accumulation of risks. In the case of Accra, Ghana, everyday disaster risks associated with multiple environmental health inadequacies in poor neighbourhoods are described, and various recommendations are made to improve public health and access to basic services. Everyday disaster risks in the form of road traffic accidents are described in case studies on Kisii and Kisumu in western Kenya. Changes to behavioural, mechanical and environmental factors are recommended. In the South African case study on the city of Cape Town, 15 years of consolidated data on everyday fire risks in informal settlements are discussed. In the case study on unplanned settlements in Dar Es Salaam, Tanzania, various disaster risks, processes causing them and measures taken by different stakeholders are identified. The latter two case studies both call for disaster risk reduction to be integrated with development and urban planning. The case study on Saint-Louis, Senegal, describes specific flood risk reduction measures in urban restructuring and development projects, as well as the need for planning to be insulated from economic and political processes. Algiers, Algeria is prone to seismic risks. This last case study describes how urbanisation exacerbates the vulnerability of the population to earthquake risk, and proposes a national disaster risk management organisation to plan for risk reduction. These case studies also recommend better education and training among the public, and advocate for more research on vulnerability, hazard and risk to influence development policy and disaster risk reduction in the city.

Africa's future is urban. Without significant changes, the future facing the poor urban majority looks bleak. Part III firstly outlines a number of challenges for disaster risk reduction deduced from the case studies, then draws a number of conclusions and proposes recommendations for a safer urban Africa. The recommendations are based on achieving gains in human security through inclusive governance and investment in the creative capacities of Africa's urban dwellers. 